\title{
Parasitic Appendicitis: A Novel Laparoscopic Approach for the Prevention of Peritoneal Contamination
}

\author{
Elbrus Zarbaliyev ${ }^{1}$ and Sebahattin Celik $\mathbb{D}^{2}$ \\ ${ }^{1}$ Department of General Surgery, Gaziosmanpaşa Hospital, Yeni Yüzyil University, İstanbul, Turkey \\ ${ }^{2}$ Department of General Surgery, Faculty of Medicine, Yuzuncu University, Van, Turkey \\ Correspondence should be addressed to Sebahattin Celik; drsebahattincelik@hotmail.com
}

Received 11 December 2017; Revised 5 April 2018; Accepted 30 April 2018; Published 24 May 2018

Academic Editor: Leigh Anne Shafer

Copyright (C) 2018 Elbrus Zarbaliyev and Sebahattin Celik. This is an open access article distributed under the Creative Commons Attribution License, which permits unrestricted use, distribution, and reproduction in any medium, provided the original work is properly cited.

\begin{abstract}
Background/Aim. Although rare, parasitic infection can cause acute appendicitis and result in contamination of the peritonea during appendectomy. The goal of this study was to summarize our experiences with parasitic appendicitis and describe a novel laparoscopic technique to prevent contamination. Method. All patients diagnosed with acute appendicitis who underwent appendectomy between January 2016 and January 2017 were included in the study. All appendectomies were performed using the standard three-port laparoscopic method, and a video recording was made of each procedure. Following separation of the mesoappendix, a single endoloop was placed in the base of the appendix, and the appendix was then transected 3-4 mm above the clamp with the aid of a thermal cauterizing/sealing device. The appendix was extracted from the $10 \mathrm{~mm}$ trocar hole below the umbilicus and placed inside a bag prepared from a glove. After pathological confirmation of parasitic appendicitis, medical records were retrospectively analyzed in each case for whether peritoneal contamination had occurred or not. Results. Out of 97 appendectomies, parasitic infection was observed in 4 cases, as confirmed by pathological examination. In two of these patients, E. vermicularis was detected, while the other two were infected with Balantidium coli. Intraoperative contamination did not occur in any of the cases, and retrospective review of the video recordings indicated no peritoneal contamination. Conclusion. As a result of the coagulation and sealing effects of thermal devices, airtight seals were created on the residual appendiceal stumps, and consequently, no contamination was observed in any of the cases.
\end{abstract}

\section{Introduction}

Acute appendicitis is the most common reason for emergency surgery and the most common reason for surgery of the gastrointestinal system (GIS) [1]. The condition is usually caused by increased pressure within the lumen following its obstruction due to fecaloid matter, after which infection develops as a result of bacterial translocation. Fecaloids and viral infection are the most common causes of appendicitis, while tumors, inflammatory bowel diseases, and parasites rarely lead to this pathology [2]. The parasite that is commonly encountered following appendectomy is E. vermicularis. In addition, parasites such as Entamoeba histolytica, Schistosoma sp., Taenia sp., Ascaris lumbricoides (Ascaris), and very rarely, Balantidium coli have also been reported to cause appendicitis $[3,4]$. Although the role of the parasites in the development of acute appendicitis has not yet been settled, parasites such as E. vermicularis and Ascaris have been reported to obstruct the appendix lumen, thus resulting in acute appendicitis [5].

While a definite connection between E. vermicularis and acute appendicitis has not yet been established, infestation with the former may present symptoms imitating acute appendicitis. E. vermicularis remains the parasite most responsible for appendicitis.

Balantidium coli is a unicellular parasite. Although it generally has an asymptomatic course, it has been shown to cause abdominal pain, dysenteric symptoms, cystitis, and pneumonia [6]. B. coli sp. has been reported to be a very rare cause of acute appendicitis [5]. 


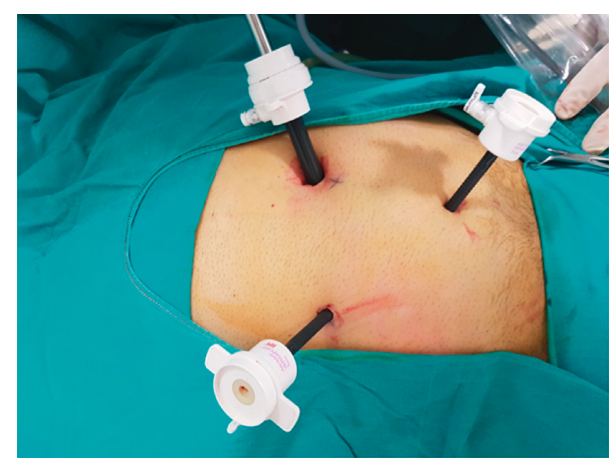

FIGURE 1: Placement of the trocar for laparoscopic appendectomy.

Currently, laparoscopic appendectomy is the standard method of appendectomy performed. Following laparoscopic appendectomy, parasitic infestation may be detected. In some studies, parasites have been detected intraoperatively, and peritoneal contaminations have been reported $[7,8]$. In our study, we retrospectively reviewed all the records of our cases of appendectomy with parasitic infection and, supplementing our data with findings reported in the literature, evaluated procedures to prevent parasitic peritoneal contamination.

\section{Patients and Methods}

All patients with a diagnosis of acute appendicitis who underwent appendectomy between January 2016 and January 2017 were retrospectively included in the study. The primary reason for selecting this time period was the fact that all the appendectomy surgeries beginning with the start date were performed by laparoscopy, with video recordings made of the procedures. By retrospectively analyzing the surgical records for the cases in which parasitic infection was observed based on the pathology results, the methods applied could be reviewed. The files, pathology results, and video recordings of the surgeries of patients diagnosed with parasitic infestations were retrospectively analyzed and reviewed.

\section{Surgical Technique}

For all patients, surgery was performed laparoscopically using the standard three-port method (Figure 1), in which one $10 \mathrm{~mm}$ and two $5 \mathrm{~mm}$ trocars were employed. Following separation of the mesoappendix, a single endoloop was placed in the base of the appendix, and the appendix was transected 3-4 $\mathrm{mm}$ above the suture by means of a thermal cauterizing device. Specimens were then placed into a bag prepared from gloves and removed through the $10 \mathrm{~mm}$ trocar hole below the umbilicus (Figures 1-4).

\section{Results}

Over the course of the one-year study period, a total of 97 patients underwent laparoscopic appendectomy surgery. In four (4\%) patients, the pathology results indicated parasitic infection. E. vermicularis was detected in two of these patients, and B. coli infestation was detected in the other two (Figures 5 and 6, resp.). One patient who was diagnosed with B. coli was a pig farmer, while the others were not involved with animal husbandry. All patients were from the Marmara region in northwestern Turkey.

The Alvarado scoring system, commonly employed in the diagnosis of acute appendicitis, was used for all patients. The mean score for the 93 patients who did not have parasitic infestation was 6.75 , while that of patients with parasitic infestation was 6.5. The average age of patients with infestation was 26.25. The average age of patients with E. vermicularis was 11.5 (11 and 12 years old), while those with B. coli had an average age of 41 (23 and 59 years old). Pathologically confirmed acute infection of the appendix and clinical fever $\left(>38^{\circ} \mathrm{C}\right)$ were only detected in one of the patients infected with $B$. coli. Intraoperative contamination was not observed in any of the cases, and retrospective review of the video records of all cases found no peritoneal contamination. All patients were discharged within 18-20 hours after surgery. In postoperative follow-up of all patients, microbiological correlation was performed and medical treatments were begun.

\section{Discussion}

E. vermicularis is an intestinal parasite usually encountered in childhood and more often in female than in male children. It is primarily found in underdeveloped countries and in regions with lower socioeconomic levels [5]. As with many other gastrointestinal nematodes, pinworms do not require a vector for transmission. Pinworm infection usually occurs through ingestion of infectious eggs due to direct anus-tomouth transfer via the fingers. This is facilitated by the perianal itch (pruritus ani), induced by the presence of pinworm eggs in the perianal folds, and commonly occurs as a result of nail biting, poor hygiene, or inadequate handwashing. One study reported that $E$. vermicularis infestation has different clinical presentations and that the parasite causes acute appendicitis [9]. Although E. vermicularis as a cause of acute appendicitis is still under debate, other studies have also concluded that it can cause acute appendicitis $[10,11]$. Different rates of E. vermicularis infestation following appendectomy have been reported for Turkey and other countries [12-14]. In our study, the rate of E. vermicularis infestation was $2 \%$. Although the diameters of the appendices in the two cases with E. vermicularis infestation were $6.5 \mathrm{~mm}$ and $6.8 \mathrm{~mm}$ based on abdominal ultrasonography (USG) results, there were no findings of acute infection, neither macroscopically nor microscopically. However, some studies have shown that acute infection accompanies E. vermicularis infestation. While mesenteric lymphadenitis was not detected in either patient, E. vermicularis is thought to cause mesenteric lymphadenitis.

Balantidiasis (also known as balantidiosis) is defined as infection of the large intestine with $B$. coli, a ciliated protozoan. $B$. coli are known to parasitize the colon, and pigs may be their primary reservoir. B. coli is a parasite that lives in domesticated (mostly pigs) and wild mammals and is the only parasite with cilia that can cause parasitic infection in 


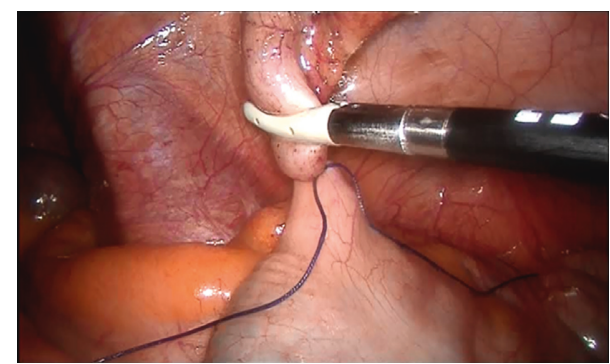

FIgURE 2: Separation of the appendix.

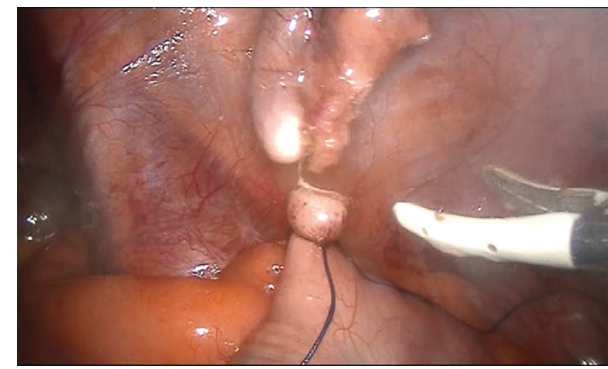

FIgURE 3: View of the residual appendix.

humans. Its prevalence varies between 0.01 and $1 \%$ in different populations [15]. Contamination by this parasite, which lives in the distal ileum and cecum areas in trophozoite form, occurs in cystic form through the fecal-oral route [16]. The parasite that occurs in trophozoite form in the intestinal lumen penetrates the intestinal mucosa by excreting hyaluronidase enzyme and can cause ulcers. Cases resulting in mortality due to intestinal perforation and peritonitis have also been reported [17]. Some studies have reported B. coli as a cause of acute appendicitis [18]. B. coli infestation was detected in two of our cases. In one of those cases, macroscopic and microscopic findings of acute infection were observed in the appendix.

The rate of parasitic infection in our study was $4 \%$. However, other studies have reported rates between 0.2 and $42 \%$ [19]. In cases of appendectomy accompanied by parasitic infection, microscopic and macroscopic findings of acute infection are generally not seen. In our study, $75 \%$ of parasitic infections did not indicate acute appendicitis. Although acute infection was not observed in these patients, there were other reasons to recommend appendectomy. As laparoscopic exploration is now possible, appendectomy is often preferred even in cases where the appendix is of normal appearance in order to treat recurrent appendix pains, and especially to reduce the potential for adnexal pathologies in female patients [20, 21]. Nonetheless, the merits of such a decision are debatable, as parasitic infestation is often seen in these cases. As a result, parasites such as E. vermicularis and Ascaris have been shown to present findings similar to appendicitis without acute infection [22, 23]. Therefore, another threat that the surgeon encounters in such cases is contamination of the peritoneal cavity by parasites existing in the appendix, which may or may not be seen macroscopically during the appendectomy.

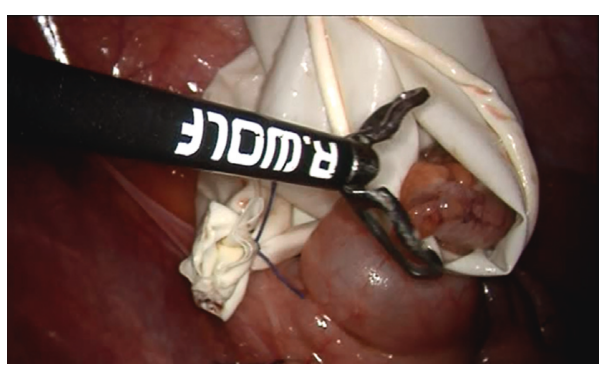

Figure 4: Removal of the appendix.

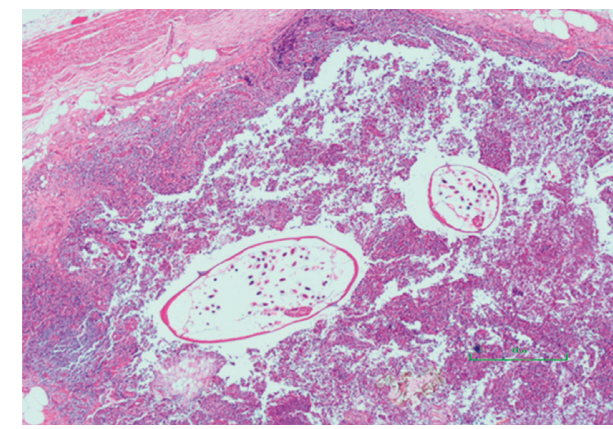

Figure 5: Appendix infested with E. vermicularis.

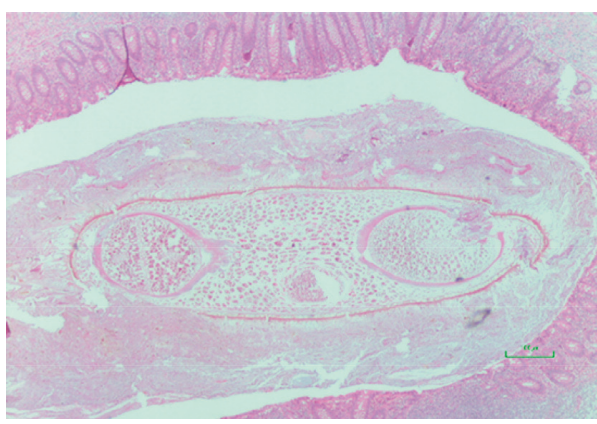

Figure 6: Appendix infested with B. coli.

In such cases, the surgeon must determine the risk of parasitic infestation before surgery, based on the patient's medical history and standard clinical and/or laboratory tests performed prior to diagnosis of acute appendicitis. Peritoneal contamination has been reported in cases of parasitic infestation, particularly with E. vermicularis. Some studies advise cleaning the peritoneal cavity following the parasitic contamination of the peritoneal cavity and provide recommendations for preventing contamination [7]. Methods such as aspiration of parasites and cauterization of the parasites localized in the appendix stump are advised. The stapler application, which is considered effective, is nonetheless costly [23]. The challenges presented by parasitic infestation, such as the ability of $E$. vermicularis to attach to the mucosa and the fact that microscopic scale parasites such as $B$. coli cannot be seen macroscopically, must be kept in mind. We used a single endoloop in all our cases and 
transected the appendix 3-4 mm above the clamp with the aid of a thermal cauterizing device (Figure 6). In the retrospective review of surgery video recordings, the appendix stump was observed to have an airtight seal as a result of coagulation, and no contamination was detected in any of our cases. It should be recalled that risk of contamination occurs during extraction of the specimen. Although this risk is eliminated when the appendectomy is performed using the stapler method, it is a costly method requiring the use of a $12 \mathrm{~mm}$ trocar. The cut side and stump port of the appendix transected using the thermal method had airtight coagulation and the lumen was closed, preventing contamination (Figure 6). The appendix was extracted from the $10 \mathrm{~mm}$ trocar hole under the umbilicus and placed inside a bag prepared from a glove. Our patients were given antiparasitic (metronidazole) treatment.

In conclusion, clinicians should be aware that parasitic infestation may cause or simply mimic appendicitis. In both situations, peritoneal contamination may occur during appendectomy. Therefore, to prevent contamination, or at least minimize its risk, the use of thermal coagulation and sealing, which both kills the parasites and seals the appendix stump, is recommended.

\section{Ethical Approval}

All procedures performed in studies involving human participants were in accordance with the ethical standards of the Ethics Committee of İstanbul Yeni Yuzyıl University, Faculty of Medicine, and with the 1964 Helsinki Declaration and its later amendments or comparable ethical standards.

\section{Consent}

Consent forms were completed by all participants.

\section{Conflicts of Interest}

The authors declare that they have no conflicts of interest.

\section{Authors' Contributions}

Elbrus Zarbaliyev and Sebahattin Celik contributed equally to surgical and medical practices, concept, design, data collection or processing, analysis or interpretation, and writing of the manuscript. Literature search was done by Elbrus Zarbaliyev.

\section{References}

[1] K. Zbierska, J. Kenig, A. Lasek et al., "Differences in the clinical course of acute appendicitis in the elderly in comparison to younger population," Polish Journal of Surgery, vol. 88, no. 3, pp. 142-146, 2016.

[2] A. Ozturk, M. Korkmaz, T. Atalay et al., "The role of doctors and patients in appendicitis perforation," American Surgeon, vol. 83, pp. 390-393, 2017.

[3] G. Calli, M. Ozbilgin, N. Yapar et al., "Acute appendicitis and coinfection with enterobiasis and taeniasis: a case report," Türkiye Parazitoloji Dergisi, vol. 38, no. 1, pp. 58-60, 2014.
[4] H. Ichikawa, J. Imai, H. Mizukami et al., "Amoebiasis presenting as acute appendicitis," Tokai Journal of Experimental and Clinical Medicine, vol. 41, pp. 227-229, 2016.

[5] O. Engin, S. Calik, B. Calik et al., "Parasitic appendicitis from past to present in Turkey," Iranian Journal of Parasitology, vol. 5, pp. 57-63, 2010.

[6] A.-P. Bellanger, E. Scherer, A. Cazorla, and F. Grenouillet, "Dysenteric syndrome due to Balantidium coli: a case report," New Microbiologica, vol. 36, pp. 203-205, 2013.

[7] A. Ariyarathenam, S. Nachimuthu, T. Tang et al., "Enterobius vermicularis infestation of the appendix and management at the time of laparoscopic appendicectomy: case series and literature review," International Journal of Surgery, vol. 8, no. 6, pp. 466-469, 2010.

[8] I. A. Nordstrand and L. K. Jayasekera, "Enterobius vermicularis and clinical appendicitis: worms in the vermiform appendix," ANZ Journal of Surgery, vol. 74, no. 11, pp. 1024-1025, 2004.

[9] J. Budd and C. Armstrong, "Role of Enterobius vermicularis in the aetiology of appendicitis," British Journal of Surgery, vol. 74, no. 8, pp. 748-749, 1987.

[10] P. Boulos and A. Cowie, "Pinworm infestation of the appendix," British Journal of Surgery, vol. 60, no. 12, pp. 975-976, 1973.

[11] G. Tolstedt, "Pinworm infestation of the appendix," American Journal of Surgery, vol. 116, no. 3, pp. 454-455, 1968.

[12] N. Akkapulu and S. Abdullazade, "Is Enterobius vermicularis infestation associated with acute appendicitis?," European Journal of Trauma and Emergency Surgery, vol. 42, no. 4, pp. 465-470, 2016.

[13] B. Isik, M. Yilmaz, N. Karadag et al., "Appendiceal Enterobius vermicularis infestation in adults," International Surgery, vol. 92, p. 221, 2007.

[14] S. Lala and V. Upadhyay, "Enterobius vermicularis and its role in paediatric appendicitis: protection or predisposition?," ANZ Journal of Surgery, vol. 86, no. 9, pp. 717-719, 2016.

[15] J. C. Esteban, C. Aguirre, R. Angles et al., "Balantidiasis in Aymara children from the northern Bolivian Altiplano," American Journal of Tropical Medicine and Hygiene, vol. 59, no. 6, pp. 922-927, 1998.

[16] F. Giarratana, D. Muscolino, G. Taviano, and G. Ziino, "Balantidium coli in pigs regularly slaughtered at abattoirs of the province of messina: hygienic observations," Open Journal of Veterinary Medicine, vol. 2, no. 2, p. 77, 2012.

[17] T. Ferry, D. Bouhour, F. De Monbrison et al., "Severe peritonitis due to Balantidium coli acquired in France," European Journal of Clinical Microbiology and Infectious Diseases, vol. 23, no. 5, pp. 393-395, 2004.

[18] L. G. Dodd, "Balantidium coli infestation as a cause of acute appendicitis," Journal of Infectious Diseases, vol. 163, no. 6, p. 1392, 1991.

[19] M. J. Arca, R. L. Gates, J. I. Groner et al., "Clinical manifestations of appendiceal pinworms in children: an institutional experience and a review of the literature," Pediatric Surgery International, vol. 20, no. 5, pp. 372-375, 2004.

[20] C. Grimes, D. Chin, C. Bailey et al., "Appendiceal faecaliths are associated with right iliac fossa pain," Annals of the Royal College of Surgeons of England, vol. 92, no. 1, pp. 61-64, 2010.

[21] L. Nemeth, D. J. Reen, D. S. O’Briain et al., "Evidence of an inflammatory pathologic condition in "normal" appendices following emergency appendectomy," Archives of Pathology and Laboratory Medicine, vol. 125, pp. 759-764, 2001.

[22] W. Symmers, "Pathology of Oxyuriasis with special reference to Granulomas due to the presence of Oxyuris vermicularis 
(Enterobius vermicularis) and its Ova in the tissues," Archives of Pathology, vol. 50, pp. 475-516, 1950.

[23] J. Dahlstrom and E. Macarthur, "Enterobius vermicularis: a possible cause of symptoms resembling appendicitis," Pathology, vol. 25, p. 5, 1993. 


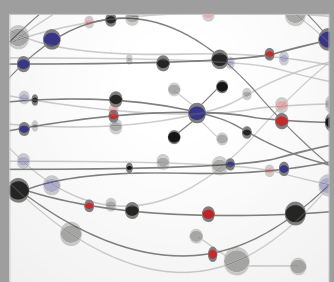

The Scientific World Journal
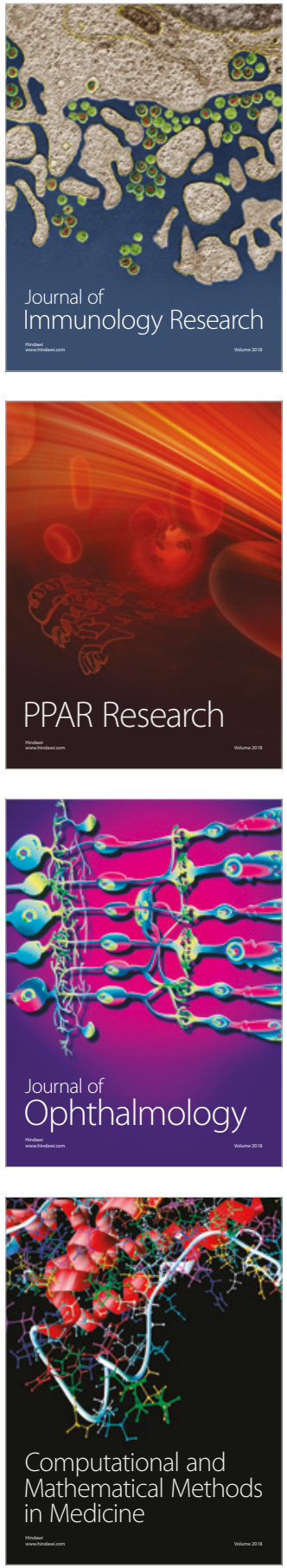

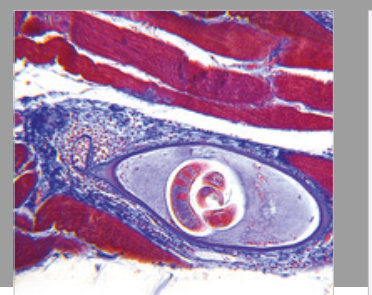

Gastroenterology Research and Practice

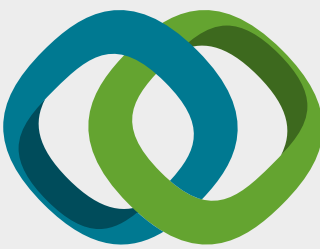

\section{Hindawi}

Submit your manuscripts at

www.hindawi.com
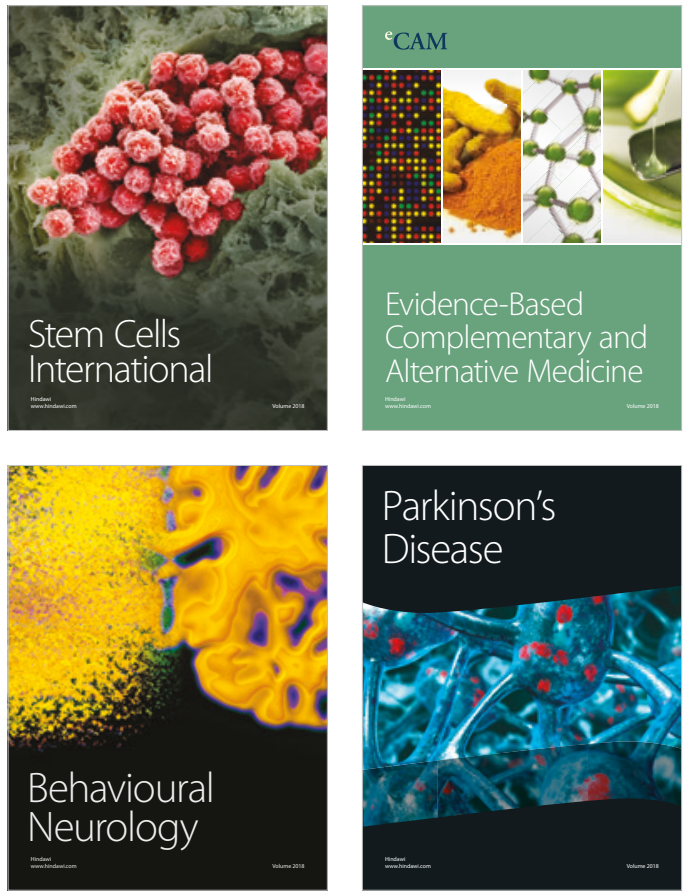

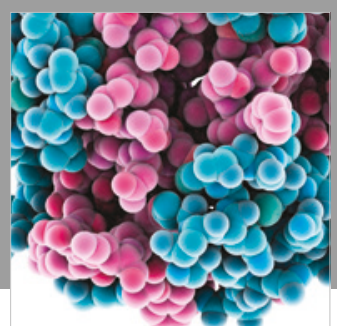

ournal of

Diabetes Research

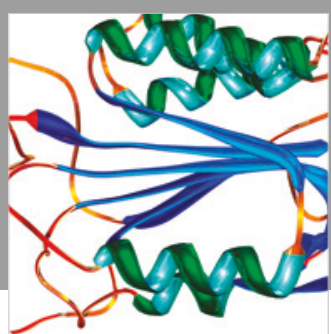

Disease Markers
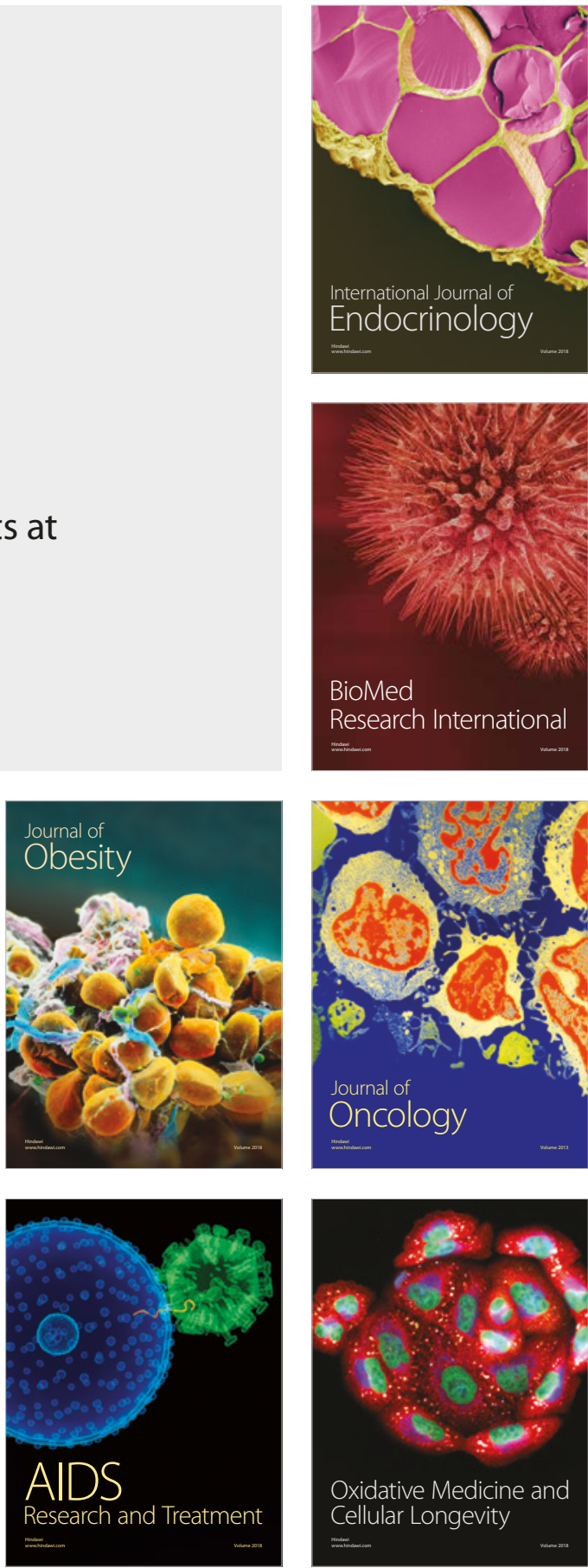